\title{
BMJ Open Opportunistic screening to detect atrial fibrillation in Aboriginal adults in Australia
}

Kylie Gwynne, ${ }^{1,2}$ Yvonne Flaskas, ${ }^{1,3}$ Ciaran O'Brien, ${ }^{1,4}$ Thomas Lee Jeffries, ${ }^{1,4}$ Debbie McCowen, ${ }^{5}$ Heather Finlayson, ${ }^{6}$ Tanya Martin, ${ }^{1,7}$ Lis Neubeck, ${ }^{7,8}$ Ben Freedman ${ }^{4,8}$

To cite: Gwynne K, Flaskas Y, O'Brien C, et al. Opportunistic screening to detect atrial fibrillation in Aboriginal adults in Australia. BMJ Open 2016;6:e013576.

doi:10.1136/bmjopen-2016013576

- Prepublication history for this paper is available online. To view these files please visit the journal online (http://dx.doi.org/10.1136/ bmjopen-2016-013576).

Received 22 July 2016 Revised 25 October 2016 Accepted 26 October 2016

CrossMark

For numbered affiliations see end of article.

Correspondence to

Kylie Gwynne;

kylie.gwynne@sydney.edu.au

\section{ABSTRACT}

Introduction: There is a 10-year gap in life expectancy between Aboriginal and non-Aboriginal Australians. The leading cause of death for Aboriginal Australians is cardiovascular disease, including myocardial infarction and stroke. Although atrial fibrillation (AF) is a known precursor to stroke there are no published studies about the prevalence of $A F$ for Aboriginal people and limited evidence about AF in indigenous populations globally. Methods and analysis: This mixed methods study will recruit and train Aboriginal health workers to use an IECG device attached to a smartphone to consecutively screen 1500 Aboriginal people aged 45 years and older. The study will quantify the proportion of people who presented for follow-up assessment and/or treatment following a non-normal screening and then estimate the prevalence and age distribution of AF of the Australian Aboriginal population. The study includes semistructured interviews with the Aboriginal health workers about the effectiveness of the iECG device in their practice as well as their perceptions of the acceptability of the device for their patients. Thematic analysis will be undertaken on the qualitative data collected in the study. If the device and approach are acceptable to the Aboriginal people and widely adopted, it may help prevent the effects of untreated $\mathrm{AF}$ including ischaemic stroke and early deaths or impairment in Aboriginal people.

Ethics and dissemination: This mixed methods study received ethics approval from the Aboriginal Health and Medical Research Council (1135/15) and the Australian Health Council of Western Australia (HREC706). Ethics approval is being sought in the Northern Territory. The findings of this study will be shared with Aboriginal communities, in peer reviewed publications and at conferences. There are Aboriginal investigators in each state/territory where the study is being conducted who have been actively involved in the study. They will also be involved in data analysis, dissemination and research translation.

Trial registration number: ACTRN12616000459426.

\section{INTRODUCTION}

Aboriginal and/or Torres Strait Islanders (hereafter Aboriginal) are the indigenous
Strengths and limitations of this study

- There is a 10-year life expectancy gap between Aboriginal and non-Aboriginal Australians and cardiovascular disease is a leading cause of early death and impairment.

- The study intends to estimate the prevalence and age distribution of known and unknown atrial fibrillation (AF) in Aboriginal people in Australia and determine the acceptability of the portable $\mathrm{EECG}$ device.

- This study uses technology which is proven to be effective in the detection of AF, was designed in collaboration with Aboriginal health organisations and is informed by the best available evidence about effective detection and treatment of health issues in Australian Aboriginal people.

- The study is novel as there are no studies about the prevalence of $\mathrm{AF}$ in Aboriginal people and the study design uses Aboriginal health workers to conduct consecutive opportunistic screenings using the iECG in the course of their usual duties.

- The study will contribute to the global evidence on indigenous peoples and AF.

people of Australia and die on average 10 years earlier than other Australians. With significantly higher rates of infant mortality, suicide and chronic disease, improving health outcomes in this population is a key priority for healthcare providers and governments. ${ }^{1}$ Many Aboriginal Australians access the healthcare system in the late stages of the disease process or in emergencies due to fear, racism and service access. ${ }^{2}{ }^{3}$ The Australian Government has a national strategy, Closing the Gap, which has established goals to close the gap in life expectancy for Aboriginal Australians within a generation. The strategy includes social determinants as well as specific health-related targets. The Prime Minister of Australia reports annually on progress toward meeting the Closing the Gap targets. ${ }^{1}$ 
Free healthcare is available in Australia. ${ }^{4}$ In addition, Aboriginal Community Controlled Health Services were established from 1971 to provide culturally specific primary healthcare services ${ }^{5}$ and all public healthcare services have explicit obligations with respect to meeting the needs to Aboriginal patients. ${ }^{3}{ }^{6}$ Aboriginal employees in the healthcare system, including Aboriginal Health Workers, play a key role in the provision of culturally competent healthcare for Aboriginal people. Aboriginal Health Workers provide primary healthcare and health literacy, and often act as brokers for Aboriginal people accessing healthcare services. ${ }^{7}$

Despite significant efforts to improve Aboriginal health outcomes, Aboriginal Australians have very high rates of cardiovascular disease particularly myocardial infarction and stroke. ${ }^{8}{ }^{9}$ Cardiovascular disease remains the leading cause of death for this population. ${ }^{10-12}$ The burden of stroke for Aboriginal people is considerable with Aboriginal people more likely than other Australians to suffer a stroke. ${ }^{12}{ }^{13}$ Atrial fibrillation (AF) is the most common sustained arrhythmia, with adults reaching the age of 40 years having a one in four lifetime chance of developing the arrhythmia. ${ }^{14}$ The risk of $\mathrm{AF}$ increases with age and individuals affected by $\mathrm{AF}$ have a five times higher risk of ischaemic stroke. Quality of life is also significantly worse for those with AF. One of the principal health issues is that $\mathrm{AF}$ is associated with $\sim 1 / 3$ of ischaemic strokes in Australia and Sweden. ${ }^{15} 16$ Strokes from AF are in general more severe than those associated with other causes, with greater mortality and disability if non-fatal. However, strokes associated with $\mathrm{AF}$ are preventable, with a $64 \%$ reduction if oral anticoagulant is prescribed. ${ }^{17} 18$

$\mathrm{AF}$ prevalence in the Australian population is estimated to rise significantly over the next two decades. ${ }^{19}$ In people with $\mathrm{AF}$, both stroke and death are greatly reduced by treatment with oral anticoagulant (by 64\% and $26 \%$ respectively). ${ }^{17}{ }^{18}$ While $\mathrm{AF}$ can be associated with symptoms, it is frequently asymptomatic which may indicate that existing documented rates of AF in Australia are a significant underestimation of the scope of the problem. ${ }^{20} 21$ To prevent strokes resulting from unknown $\mathrm{AF}$, screening for asymptomatic AF could be helpful. ${ }^{22}$

There is very limited information on the rates of $\mathrm{AF}$ in Australian Aboriginal people, and the only studies available have come from hospitalisation data after an admission. These studies found a much higher age-standardised incidence of AF in Aboriginal than in non-Aboriginal patients. This is particularly marked in the younger age groups, with ratios of age standardised incidence rates of $\mathrm{AF}$ for Aboriginal people being 3.6 for men and 5.4 for women compared to non-Aboriginal people between the ages of 20 and 54 years. On average, Aboriginal people develop AF almost 20 years earlier than their non-Aboriginal counterparts, and even more concerning is the high rate of associated comorbidities found in this subset versus the wider Australian population. $^{20} 21$ Risk factors for AF such as hypertension, diabetes, obesity, physical inactivity, chronic kidney disease, acute rheumatic fever and rheumatic heart disease are all more common in Aboriginal people and at a younger age than in non-Aboriginal people..$^{202123}$ This uneven burden of comorbidity results in $\mathrm{CHA}_{2} \mathrm{DS}_{2} \mathrm{VASc}$ scores (a score developed to indicate risk of stroke) of $\geq 2$, indicating risk sufficient to recommend anticoagulation in 53\% of Aboriginal people aged below 55 years, and $73 \%$ in those aged 55-64 years, compared to only $14 \%$ and $28 \%$, respectively, in non-Aboriginal people of the same age. ${ }^{20}$ Aboriginal people therefore face a double jeopardy of increased AF incidence at a younger age and an increased risk of stroke when AF occurs. ${ }^{20} 21$

Accordingly, our study will take a preventative approach and opportunistically screen patients for $\mathrm{AF}$ at a younger age, starting at 45 years, before associated cardiovascular complications, like stroke, occur. Aboriginal people 45 years and above make up just $18 \%$ of the Aboriginal population in Australia. ${ }^{24}$ By comparison the total Australian population aged 45 years and over is $39.6 \% .^{24}$ Previous studies have assessed symptomatic AF in hospitalised patients, so our study is novel in that no previous study has assessed the incidence of asymptomatic AF in Aboriginal people. ${ }^{20} 2125$

There is some evidence in the literature for the efficacy of opportunistic screening in the sexual and reproductive health of Aboriginal people. ${ }^{26-29}$ To be effective, opportunistic screening must be undertaken in a culturally competent manner as the cultural competence of the health service is associated with the likelihood that Aboriginal people access services. ${ }^{30}$ Critically important is that opportunistic screening must include pathways for further assessment and treatment, and access must be actively facilitated where necessary. ${ }^{31}$ Further, opportunistic screening should include improving health literacy so that Aboriginal people are better informed about their health and therefore more likely to identify potential health issues earlier. ${ }^{32} 33$ There are no studies of opportunistic screening of Aboriginal people for cardiovascular disease or AF.

Our study will estimate the prevalence and age distribution of asymptomatic AF in Aboriginal Australians. There are a number of unique challenges in identifying Aboriginal people with asymptomatic AF: the population is small (just under $3 \%$ of the Australian population) ${ }^{1}$ and is not reliably identified within the healthcare setting; the population is also widely dispersed; ${ }^{34}$ less likely to access healthcare services; likely to have lower health literacy; and less likely to seek healthcare assessment or treatment at the early signs. ${ }^{35}$ This study explicitly addresses each of these issues through use of a portable single-lead iECG device (Kardia) which can be used by a lay person with minimal training. The iECG device has been successfully used by non-physician health personnel in non-Aboriginal populations in Australia. ${ }^{22} 36-38$

The overall goal of the study is to help prevent the effects of untreated AF in Aboriginal people, particularly 
ischaemic stroke which may result in early death or impairment. The study has three aims, to:

1. Determine the acceptability of the portable iECG device to diagnose AF in Aboriginal people and facilitate access to further assessment and treatment;

2. Estimate the prevalence and age distribution of both known and unknown $\mathrm{AF}$ in Aboriginal people in Australia;

3. Improve health literacy in Aboriginal people and iECG screeners.

As there is limited evidence about the prevalence of $\mathrm{AF}$ in indigenous populations globally ${ }^{25}$ this study should also contribute to the global picture of AF prevalence in indigenous peoples.

\section{METHODS AND ANALYSIS \\ Study design}

This is a mixed methods study. We will use quantitative methods to determine the proportion of participants with a non-normal result who presented for follow-up assessment and treatment, and to estimate the prevalence and age distribution of $\mathrm{AF}$ in Aboriginal people. Qualitative methods will be used to determine the acceptability of the iECG as a screening tool for iECG screeners and Aboriginal participants, and the effect of the intervention on improving health literacy in Aboriginal patients.

The study will take place in communities in New South Wales, Northern Territory and Western Australia in collaboration with Aboriginal Community Controlled Health Services and other services which meet the needs of Aboriginal people in those communities (eg, hospital, dental service, pharmacy and community centre). Each participating service will nominate local Aboriginal health or health-related workers with a good understanding of the local healthcare system and a willingness to participate in the study.

\section{Data collection method}

The local Aboriginal healthcare workforce have been identified to participate in the study as data collectors because they are likely to be trusted by Aboriginal people and have a high level of cultural competence, understand the local health system and are likely to be able to facilitate and expedite access to the local health system. Cultural competence is well established in the literature as a critical factor in Aboriginal people participating in healthcare services. ${ }^{39-41}$ These workers will be termed iECG screeners in this study. The iECG screeners will receive training in the use of the iECG device, consent processes, cardiovascular health promotion and treatment, data collection and the clinical pathway for patients with a non-normal result and will conduct the screenings as part of their usual interactions with patients in the community, home or clinic. There is some evidence in the peer-reviewed literature for the efficacy of each of the study design elements with Aboriginal people. ${ }^{27}$ 29-31 42

The iECG has been chosen as the screening tool for this study because it has been successful with other populations, ${ }^{22}{ }^{36-38}$ it is small (clips onto the back of most smartphones); can be used by anyone with minimal training; and records a single-lead ECG in $\sim 30$ s. A validated algorithm allows reliable detection of $\mathrm{AF}$ and other arrhythmias in real-time. ${ }^{22}$ This device enables cost-effective community-based screening, including rural and remote locations. The device is accurate and Food and Drug Administration and Therapeutic Goods Administration approved (ARTG Identifier 208100) and has been used in studies to identify AF in Metropolitan Sydney ${ }^{22}$ and Melbourne. After the ECG is completed, the data is transmitted to the password encrypted and HIPPAA compliant Kardia proprietary server. Another account will store de-identified ECG screening data for this study.

Participating health services will be supplied with the iECG device and smartphone for each health worker who will be undertaking screenings in the study. The smartphone will have an activated sim card to enable the iECG software to transmit the ECG via the telephone data network. The participating health service will keep the iECG device after the completion of the study to benefit their health service.

\section{Sampling strategy}

Gaining informed consent and conducting the screenings will occur opportunistically within the course of usual duties for a range of qualified and unqualified iECG screeners. iECG screeners will invite consecutive patients to participate in the study which should reduce bias in the sample. A total of 1500 people represent $1 \%$ of the Aboriginal population in Australia aged 45 years and older and is therefore a reasonable sample to estimate prevalence. If we assume a prevalence of $\mathrm{AF}$ of $3 \%$ in this population, then the $95 \%$ CI of this would be $2.0 \%$ to $4.0 \%$ with this sample size.

Thirty iECG screeners will conduct 50 screenings on eligible patients in order to reach a total of 1500 screenings. Given the additional time required to gain informed consent for patients to join the study and the wide-ranging roles and responsibilities of Aboriginal workers in the healthcare system, the study explicitly limits each screener to 50 screenings. Once they have completed the 50 screenings for the study they can retain the device and use it in their usual practice.

The eligibility criteria for this study are:

1. Aboriginal heritage;

2. Aged 45 years or more;

3. Living in New South Wales, Northern Territory or Western Australia.

\section{Procedure}

Eligible participants will be formally consented into the study by an Aboriginal iECG screener. Participants will 
receive an information sheet explaining the study and a plain English and pictorial information sheet setting out the risk factors for cardiovascular disease, the ways to reduce risk and promote heath, a straightforward explanation of the symptoms of a heart disease and what to do if experiencing those symptoms.

The iECG has three possible results normal, possible AF or unclassified. Participants who record a result other than normal will be referred for a confirmatory 12-lead ECG and individual management plan. This management plan will be supported by the iECG screener and will proceed according to the agreed pathway. The assessment and treatment pathways for patients with a non-normal result will be negotiated, agreed and documented with each community before starting the study in that site. A registered nurse associated with the study will review all cases where a patient has a non-normal result, within 24 hours of the screening and take all steps to ensure that the participant has accessed further assessment and treatment where indicated. The registered nurse will follow-up with every patient with a non-normal result and facilitate access to further assessment and treatment where this is indicated. The registered nurse will also record in a database whether or not the patient with a non-normal iECG attended for a 12-lead ECG, whether or not they had AF and whether or not they knew they had AF prior to the screening. The fidelity of the intervention will be assessed quantitatively by recording the number of patients who do not complete the protocol and qualitatively through interviews with iECG screeners and the registered nurses.

Once the 1500 screenings have been completed, data will be exported from the AliveCor server and analysed to estimate the prevalence and age distribution of $\mathrm{AF}$ in Aboriginal people in Australia. The interviewer-assisted surveys will be conducted face-to-face or via telephone with the iECG screeners by a member of the research team. This will include, wherever possible, iECG screeners who did not complete 50 screenings. The surveys will identify the enabling factors and barriers for: (1) Aboriginal workers using the iECG in the course of their practice and (2) Aboriginal patients' receptiveness to the $\mathrm{iECG}$ as perceived by the iECG screeners.

\section{Data analysis}

Descriptive statistics (means and proportions including their CIs) will be analysed using SPSS software, V.22 (SPSS , Chicago, Illinois, USA). The $\chi^{2}$ test will be used to examine demographic differences including age and sex.

The qualitative analysis will be based on published methods for qualitative research in healthcare. ${ }^{43}$ All interviews will be transcribed in full and downloaded into NvivoV.11 for analysis.

\section{ETHICS AND DISSEMINATION}

Ethics approval is being sought in the Northern Territory.

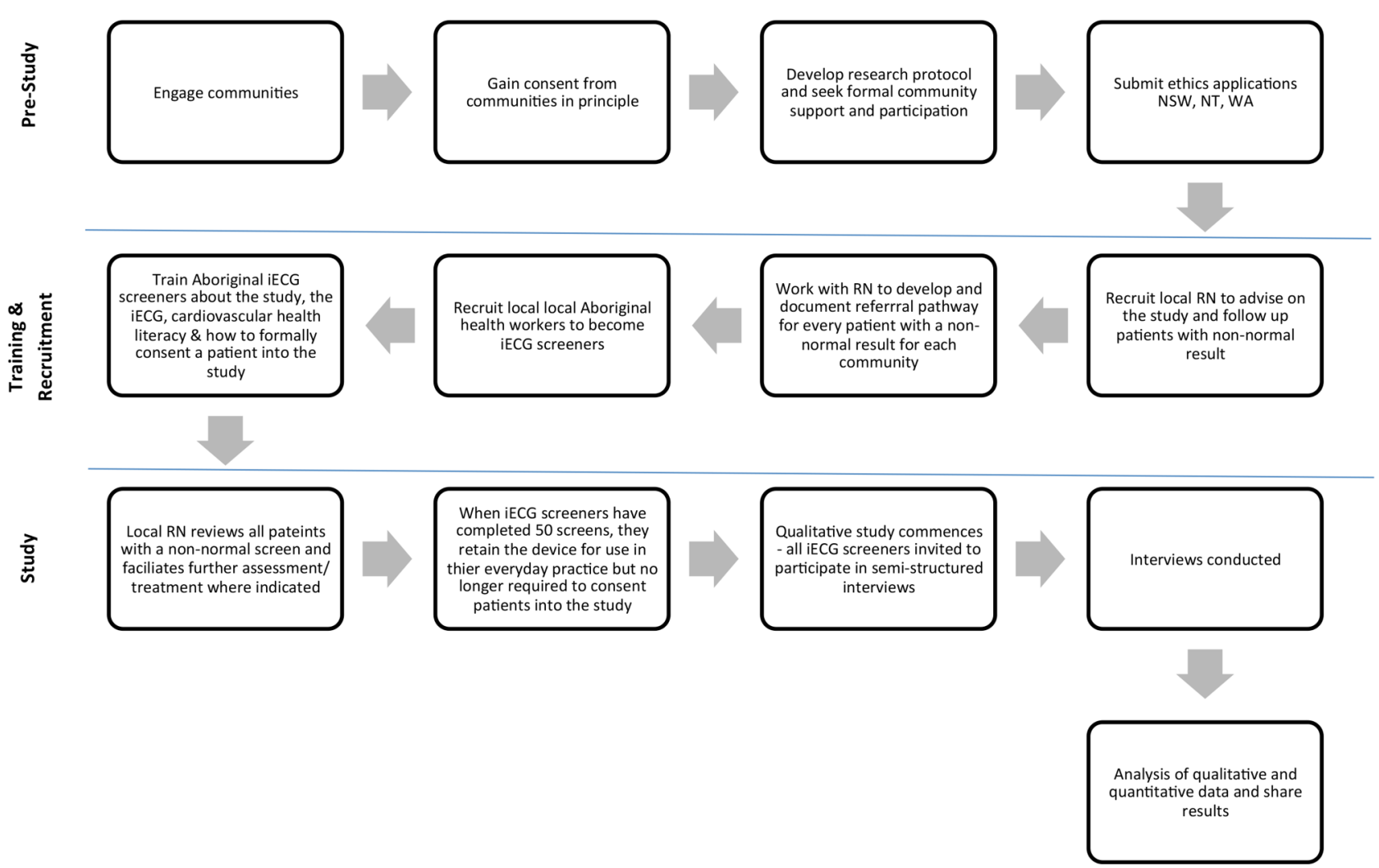

Figure 1 Flow chart of the study. NSW, New South Wales; NT, northern territory; RN, registered nurse; WA, Western Australia. 
It is a requirement of the Ethics Committee of the Aboriginal Health and Medical Research Council that Aboriginal communities are engaged prior to the study to inform the study design. The process of working with communities to design the study such that they could write letters of support, took $\sim 9$ months. The process for this study is detailed in figure 1 .

The findings of this study will be shared with Aboriginal communities, the Aboriginal Health and Medical Research Council, and in peer-reviewed publications and at conferences. The findings will also contribute to the global picture of $\mathrm{AF}$ prevalence and age distribution, and if widely adopted will improve timely detection and treatment of AF in Aboriginal people.

\section{STRENGTHS AND LIMITATIONS OF THE STUDY}

The strengths of the study are that it uses technology which is proven to be effective in the detection of AF; the study design was developed in collaboration Aboriginal health organisations and is informed by the best available evidence about effective detection of health issues and treatment of Australian Aboriginal people. However, the evidence for effective detection and treatment of Aboriginal people is sparse and there are no studies about opportunistic screening of Aboriginal people for cardiovascular disease. The available evidence indicates that Australian Aboriginal and New Zealand Maori populations experience AF at a younger age than other populations. This study includes Aboriginal people aged 45 years and older. Depending on the findings of this study, future studies may include younger people.

We are conducting opportunistic screening for known and unknown AF in people accessing healthcare services and are recruiting predominantly from rural and remote parts of Australia, with some regional sites. This will inevitably bias our sample. To reduce this we have instructed our screeners to be as systematic as possible. This will reduce the bias of haphazard or selective sampling. While consecutive sampling is not equivalent to random sampling it is appropriate for this population group. Our sample will not be completely representative of Aboriginal people across Australia as we are concentrating on rural and regional areas. The opportunistic sampling and its potential compromise to representativeness is a limitation of the study.

Given the burden of cardiovascular disease borne by Aboriginal Australians and the estimated significant rise of AF prevalence in Australia, this study is an important next step in preventing premature death or impairment of Aboriginal people from stroke. This mixed methods study brings together the best available evidence on AF, opportunistic screening and Aboriginal Australians to estimate the prevalence and age distribution of known and unknown AF in Aboriginal people in Australia and determine the acceptability of the portable iECG device.
Author affiliations

${ }^{1}$ Poche Centre for Indigenous Health, The University of Sydney, Camperdown, New South Wales, Australia

${ }^{2}$ Faculty of Health Sciences, The University of Sydney, Camperdown, New South Wales, Australia

${ }^{3}$ Faculty of Dentistry, The University of Sydney, Westmead, New South Wales, Australia

${ }^{4}$ Sydney Medical School, The University of Sydney, Camperdown, New South Wales, Australia

${ }^{5}$ Armajun Aboriginal Health Service, Inverell, New South Wales, Australia ${ }^{6}$ Brewarrina Multipurpose Service, Brewarrina, New South Wales, Australia ${ }^{7}$ Sydney Nursing School, The University of Sydney, Camperdown, New South Wales, Australia

${ }^{8}$ Charles Perkins Centre, The University of Sydney, Sydney, New South Wales, Australia

Twitter Follow kylie gwynne at @kyleis43

Acknowledgements This development and planning of this study has required the assistance and advice of friends and colleagues working in Aboriginal health in rural and remote Australia. The authors would particularly like to thank Hellen Mannix, Donna Taylor, Sandra Thompson, Sandra Hamilton and Kerry Taylor.

Contributors KG, BF, LN, HF, DMcC, TM and YF designed the study. KG, YF and BF secured the funding for the trial. KG, YF, TLJ, CO'B and BF handled the ethical approval regarding the trial. $K G$ was also involved in preparing of the manuscript and registered the trial. All authors reviewed and approved the final manuscript.

Funding This work was supported by the Poche Centre for Indigenous Health at the University of Sydney and a 2016 Heart Foundation Vanguard Grant (101059). In-kind support is provided by Poche Centres for Indigenous Health in Western Australia and Northern Territory, the Charles Perkins Centre at the University of Sydney, Sydney Medical School and Armajun Aboriginal Health Service. Additional funding is from an anonymous charitable foundation.

Competing interests BF has received research grants to conduct investigator-initiated studies by BMS/Pfizer, Bayer Pharma and Boehringer-Ingelheim, consultant for Bayer Pharma, BMS/Pfizer, Boehringer-Ingelheim, Servier, Astra-Zeneca and Gilead, and speaker for Bayer Pharma, BMS/Pfizer, AstraZeneca. LN has received grants and honoraria from Pfizer BMS, Boehringer Ingelheim and Bayer outside the submitted work.

Ethics approval Ethics approval has been granted for the NSW study through the Aboriginal Health and Medical Research Council (1135/15) and Western Australia by the Australian Health Council of Western Australia (HREC706).

Provenance and peer review Not commissioned; externally peer reviewed.

Data sharing statement All de-identified data will be shared with all investigators on the study.

Open Access This is an Open Access article distributed in accordance with the Creative Commons Attribution Non Commercial (CC BY-NC 4.0) license, which permits others to distribute, remix, adapt, build upon this work noncommercially, and license their derivative works on different terms, provided the original work is properly cited and the use is non-commercial. See: http:// creativecommons.org/licenses/by-nc/4.0/

\section{REFERENCES}

1. Australian Government. Closing the Gap Prime Minister's Report. 2016. http://closingthegap.dpmc.gov.au/assets/pdfs/closing_the_ gap_report_2016.pdf

2. Australian Institute of Health and Welfare. Australia's health 2014. Canberra: AIHW, 2014 Contract No.: AUS178.

3. Bainbridge R, McCalman J, Clifford A, et al. Cultural competency in the delivery of health services for Indigenous people. Canberra: Australian Institute of Health and Welfare, 2015.

4. Australian Government Department of Human Services Medicare Services Canberra: Australian Government (18 September 2016). https://www.humanservices.gov.au/customer/subjects/ medicare-services 
5. Panaretto KS, Wenitong M, Button S, et al. Aboriginal community controlled health services: leading the way in primary care. Med J Aust. 2014;200:649-52.

6. Clifford A, McCalman J, Bainbridge R, et al. Interventions to improve cultural competency in healthcare for Indigenous peoples of Australia, New Zealand, Canada and the USA: a systematic review. Int J Qual Healthcare 2015;27:89-98.

7. Gwynne K, Lincoln M. Developing the rural health workforce to improve Australian Aboriginal and Torres Strait Islander health outcomes: a systematic review. Aust Health Rev 2016;16.

8. Bradshaw PJ, Alfonso HS, Finn J, et al. A comparison of coronary heart disease event rates among urban Australian Aboriginal people and a matched non-Aboriginal population. J Epidemiol Community Health 2011;65:315-19.

9. Thompson PL, Bradshaw PJ, Veroni M, et al. Cardiovascular risk among urban Aboriginal people. Med J Aust 2003;179:143-6.

10. Brown A. Acute coronary syndromes in indigenous Australians: opportunities for improving outcomes across the continuum of care. Heart Lung Circ 2010;19:325-36.

11. Australian Bureau of Statistics. Deaths, Australia, 2013. Canberra: Australian Bureau of Statistics, 2014

12. Katzenellenbogen JM, Voss $\mathrm{T}$, et al. Burden of stroke in indigenous Western Australians: a study using data linkage. Stroke 2011;42:1515-21.

13. You J, Condon JR, Zhao Y, et al. Stroke incidence and case-fatality among Indigenous and non-Indigenous populations in the Northern Territory of Australia, 1999-2011. Int J Stroke 2015;10:716-22.

14. Lloyd-Jones D, Wang TJ, Leip EP, et al. Lifetime risk for development of atrial fibrillation. The Framingham Heart Study. Circulation 2004;110:1024-6.

15. Friberg L, Hammar N, Ringh M, et al. Stroke prophylaxis in atrial fibrillation: who gets it and who does not? Report from the Stockholm Cohort-study on Atrial Fibrillation (SCAF-study). Eur Heart J 2006;27:1954-64.

16. Leyden JM, Kleinig TJ, Newbury J, et al. Adelaide Stroke Incidence Study declining stroke Rates but many preventable cardioembolic strokes. Stroke 2013;44:1226-31.

17. Ruff CT, Giugliano R, Braunwald E, et al. Comparison of the efficacy and safety of new oral anticoagulants with warfarin in patients with atrial fibrillation: a meta-analysis of randomised trials. Lancet 2014;383:955-62

18. Hart RG, Pearce LA, Aguilar Ml. Meta-analysis: antithrombotic therapy to prevent stroke in patients who have nonvalvular atrial fibrillation. Ann Intern Med 2007;146:857-67.

19. Ball J, Thompson DR, Ski CF, et al. Estimating the current and future prevalence of atrial fibrillation in the Australian adult population. Med J Aust 2015;202:32-5.

20. Katzenellenbogen JM, Teng THK, Lopez D, et al. Initial hospitalisation for atrial fibrillation in aboriginal and non-aboriginal populations in Western Australia. Heart 2015;101:712-19.

21. Wong CX, Brooks $\mathrm{A}$, Cheng $\mathrm{YH}$, et al. Atrial fibrillation in Indigenous and non-Indigenous Australians: a cross-sectional study. BMJ Open 2014:4:e006242.

22. Lowres N, Neubeck L, Salkeld G, et al. Feasibility and cost-effectiveness of stroke prevention through community screening for atrial fibrillation using iPhone ECG in pharmacies. The SEARCH-AF study. Thrombosis Haemost 2014;111:1167-76.

23. Australian Institute of Health and Welfare. Rheumatic heart disease and acute rheumatic fever in Australia: 1996-2012. Canberra: AlHW, 2013.

24. Australian Bureau of Statistics. Estimates and projections, Aboriginal and Torres Strait Islander Australians, 2001 to 2026. Canberra: Australian Bureau of Statistics, 2014.
25. Katzenellenbogen JM, Woods JA, Teng TH, et al. Atrial fibrillation in the Indigenous populations of Australia, Canada, New Zealand, and the United States: a systematic scoping review. BMC Cardiovasc Disord 2015;15:87.

26. Fairbairn AP, Tyler H, Su JY, et al. Risk factors and associations for the diagnosis of sexually transmitted infections in aboriginal women presenting to the Alice Springs hospital emergency department. Emerg Med Australas 2010;22:216-23.

27. Hunt JM, Gless GL, Straton JA. Pap smear screening at an urban aboriginal health service: report of a practice audit and an evaluation of recruitment strategies. Aust N Z J Public Health 1998;22:720-5.

28. Shaw K, Stephens N, Coleman D, et al. Role of the general practitioner in testing for genital Chlamydia trachomatis infection: an analysis of enhanced surveillance data. Sex Health 2009;6:208-12.

29. Zecchin R, McNulty K, Rull L, et al. Nurse-led opportunistic screening during NAIDOC Week 2011. Aust Nurs J 2011;19:36.

30. Smith JD, O'Dea K, McDermott R, et al. Educating to improve population health outcomes in chronic disease: an innovative workforce initiative across remote, rural and Indigenous communities in northern Australia. Rural Remote Health 2006;6:606.

31. Bailie RS, Si D, O'Donoghue L, et al. Indigenous health: effective and sustainable health services through continuous quality improvement. Med J Aust 2007;186:525-7.

32. Vass A, Mitchell A, Dhurrkay Y. Health literacy and Australian Indigenous peoples: an analysis of the role of language and worldview. Health Promot J Aust 2011;22 33-7.

33. Australian Commission on Safety and Quality in Healthcare. Health literacy: taking action to improve safety and quality. Sydney. 2014.

34. Australian Institute of Health and Welfare. Access to health services for Aboriginal and Torres Strait Islander people. Canberra, Australia. 2011.

35. Barnett L, Kendall E. Culturally appropriate methods for enhancing the participation of Aboriginal Australians in health-promoting programs. Health Promot J Aust 2011;22:27-32.

36. Orchard J, Freedman SB, Lowres N, et al. iPhone ECG screening by practice nurses and receptionists for atrial fibrillation in general practice: the GP-SEARCH qualitative pilot study. Aust Fam Physician 2014;43:315-19.

37. Lau JK, Lowres N, Neubeck L, et al. iPhone ECG application for community screening to detect silent atrial fibrillation: a novel technology to prevent stroke. Int J Cardiol 2013;165:193-4.

38. Orchard JLN, Freedman B, et al. Screening for atrial fibrillation during influenza vaccinations by primary care nurses using a smartphone electrocardiograph (iECG): a feasibility study. European Journal of Preventive Cardiology. European Journal of Preventive Cardiology. 2016; http://cpr.sagepub.com/content/23/16/1783.

39. Barclay L, Kruske S, Bar-Zeev S, et al. Improving Aboriginal maternal and infant health services in the 'Top End' of Australia; synthesis of the findings of a health services research program aimed at engaging stakeholders, developing research capacity and embedding change. BMC Health Serv Res 2014;14:241.

40. Kildea S, Stapleton H, Murphy R, et al. The Murri clinic: a comparative retrospective study of an antenatal clinic developed for Aboriginal and Torres Strait Islander women. BMC Pregnancy Childbirth 2012:12:159.

41. Turner AW, Xie J, Arnold AL, et al. Eye health service access and utilization in the National Indigenous Eye Health Survey. Clin Experiment Ophthalmol 2011;39:598-603.

42. Gador-Whyte AP, Wakerman J, Campbell D, et al. Cost of best-practice primary care management of chronic disease in a remote Aboriginal community. Med J Aust 2014;200:663-6.

43. Pope C, Mays M. Qualitative reserach in healthcare. 3rd edn. UK: Blackwell Publishing, 2006. 